Indian Growth is Not Overestimated: Mr. Subramanian You Got it Wrong

Ashima Goyal, Abhishek Kumar

Indira Gandhi Institute of Development Research, Mumbai June 2019 


\title{
Indian Growth is Not Overestimated: Mr. Subramanian You Got it Wrong
}

\author{
Ashima Goyal, Abhishek Kumar
}

Email(corresponding author): ashima@igidr.ac.in

\begin{abstract}
Subramanian (2019) argues that indicators like growth in export, import and private credit can be used to predict economic growth across countries. He finds these indicators were able to predict Indian growth before 2011 but fail to do so after the GDP estimation methodology was changed in 2011. This implies Indian growth was overestimated by $2.5 \%$ per annum post 2011 . But on removing various flaws in his data and procedures used, we find these indicators underestimate growth before 2011 too. The most reasonable specification suggests that the underestimation before 2011 was higher than underestimation post 2011. Moreover, growth in a large number of countries is found to be either overestimated or underestimated, based on these indicators. His empirical design is therefore flawed. These regressions cannot be used for predicting growth or for concluding Indian growth is overestimated or for pointing to problems in the estimation methodology.
\end{abstract}

Keywords: Indian growth; overestimation; growth indicators; prediction regressions; impact evaluation

JEL Code: O47, 053 


\title{
Indian Growth is Not Overestimated: Mr. Subramanian You Got it Wrong
}

\author{
Ashima Goyal* \\ Abhishek Kumar ${ }^{\dagger}$
}

June 19, 2019

\begin{abstract}
Subramanian (2019) argues that indicators like growth in export, import and private credit can be used to predict economic growth across countries. He finds these indicators were able to predict Indian growth before 2011 but fail to do so after the GDP estimation methodology was changed in 2011. This implies Indian growth was overestimated by $2.5 \%$ per annum post 2011 . But on removing various flaws in his data and procedures used, we find these indicators underestimate growth before 2011 too. The most reasonable specification suggests that the underestimation before 2011 was higher than underestimation post 2011. Moreover, growth in a large number of countries is found to be either overestimated or underestimated, based on these indicators. His empirical design is therefore flawed. These regressions cannot be used for predicting growth or for concluding Indian growth is overestimated or for pointing to problems in the estimation methodology.
\end{abstract}

*Professor, Indira Gandhi Institute of Development Research (IGIDR), Gen. A. K. Vaidya Marg, Goregaon (E) Mumbai 400065, India. E-mail: ashima@igidr.ac.in

${ }^{\dagger}$ Corresponding author: Indira Gandhi Institute of Development Research (IGIDR), Gen. A. K. Vaidya Marg, Goregaon (E) Mumbai 400065, India. E-mail: abhishek@igidr.ac.in 
Keywords: Indian growth; overestimation; growth indicators; prediction regressions; impact evaluation

JEL Codes: O47, O53

\section{Why This Paper?}

Using a cross country regression, Subramanian (2019, AS hereafter) claims that India has overestimated growth by $2.5 \%$ per annum between $2012-16$. This claim has attracted lot of attention. One view is since a former chief economic advisor has casted doubt, based on evidence that he says is robust, it is difficult to trust Indian growth numbers anymore. An independent inquiry is warranted. He has himself asked for a serious debate. But there are also criticisms of his poor specification that point to problems with using cross country regressions to predict the growth of a country.

We undertake that debate in this paper, pointing out serious conceptual and econometric flaws. But since it is possible to argue that in an impact evaluation (natural experiment) setup, specification is of second order importance, we also show the results do not hold in his own specification. He is not only trying to predict growth, but also trying to establish causality-that a methodology change led to overestimation. It is important to invalidate the empirical design of the causal story.

Using his impact evaluation framework only, we will show that he ran his regression without doing enough internal consistency tests and made a wild claim, that the evidence did not warrant. Certain conditions need to be fulfilled for making any inference from impact evaluation design. We will show one by one that he did not do falsification tests with the seriousness expected of an ex-chief economic advisor whose views have global impact. He did some robustness analysis in cross sectional regressions, but ignored warnings coming from it. Due diligence required doing tests also in the panel and other regressions before making public claims. Had he done these tests, then there would have been no claim to make, as we show in this paper. His impact evaluation design does not pass any falsification test. His empirical framework is flawed, therefore, and any 
conclusion from it is completely unfounded.

\section{Introduction}

Estimation of gross domestic product (GDP) in any economy comes from a painstaking grass-roots process. An econometric exercise can never be a substitute. Indian statistical agencies have a long history. Stalwarts associated with them set up robust processes to measure GDP even in a difficult economy like India with poor data availability for a large informal sector. Periodic revisions are required to keep pace with the changing structure of the economy.

The shift to the base 2011-12 involved major revisions, and therefore generated a healthy debate (Dholakia, Nagraj and Pandya (2018), Nagraj and Srinivasan (2016), Goyal (2015) and Dholakia (2015)). The use of larger, newer more representative databases, more consistency across categories, conceptual improvements including for the informal sector and shift towards international practices undertaken were all required, however. Since new databases take time to stabilise, changes in subsequent revisions as well as back-casting have also been large. But potential sources of errors have been decreasing over time. For example, the much larger MCA-21 database of companies arising from statutory filing under the Companies Act of registered company annual reports is being cleaned out for dummy companies. But no one thinks we should go back to the earlier sample of 2,500 companies. Problems arising from deflation using CPI or WPI in a period when the two had large divergences are shrinking as the two converge. Therefore Arvind Subramanian's recent argument that average growth is over-estimated by 2.5 percent since 2011 is difficult to accept.

AS motivates his contention with correlations of growth using a range of indicators. Many of these correlations became negative post 2011. His correlations after 2011 are obtained from only five observations. Small sample problems imply they cannot be taken seriously. The largest decline has happened in growth of sales of heavy vehicle, but the correlation of that has increased with growth. Ideally this should have fallen. 
His serious analysis starts with using regressions to predict GDP based on a few macroeconomic indicators that predict well, but are not produced by government statistical agencies involved in the estimation of GDP. The indicators he settles on are export and imports of goods and services, domestic credit to the private sector and consumption of electricity in the economy. He then tests the impact of the exogenous variation of methodology change in predictability regressions for growth. He gets a predicted value of Indian GDP that is lower than the Central Statistical Organization (CSO) estimations after 2011. He obtains growth predictions in two periods (first, 2002-11) and (second, 2012-16). Since the predicted is same as actual (statistically) in the first period but falls short substantially in the second period, it implies that measured growth in the latter period was higher than what is predicted by indicators that used to predict it well. Assuming nothing else happened with change in methodology that would affect growth (no confounding factors), he concludes that the methodology change in 2011 has led to overestimation of growth ${ }^{1}$. Partial exercises suggest the results are robust. A panel regression with country and year fixed effects is also done with similar results.

There are three important conditions that must be satisfied for the validity of his claim. First, these indicators must be able to predict Indian growth before the 2011 methodology change. This is akin to parallel trend assumption widely used by the econometrician in policy analysis work. Second, nothing else should have happened with change in methodology that may also affect growth independently. This is akin to absence of confounding factors. It is very easy to provide presence of confounding factors in regressions of macro variables and therefore we will not use this route to refute his claim. Third, methodology change is an exogenous variation for India only ${ }^{2}$, so if we give this treatment to other countries, their growth must not be overestimated or underestimated post 2011 as nothing changed in these countries.

\footnotetext{
${ }^{1}$ Overestimation of growth implies overestimation of GDP and in this paper we use this interchangeably.

${ }^{2}$ One can disagree here as well, as there is a possibility that methodology change was endogenous in response to earlier underestimation of growth. We will not try to counter this assumptions, which can also be done easily.
} 
We will test whether these variables were able to predict growth in India before 2011. If they were not able to, then there is no reason to believe that these variables should be able to predict it after 2011. We will also test whether these indicators can predict growth of other countries post 2011. We will call these tests falsification test. We will do Placebo tests exercise for different time spans. Inability to pass these tests would invalidate his empirical design and therefore all claims made by AS. He did do robustness analysis but only for cross-section not for the panel and ignored troubling patterns in placebo regressions.

Since his data set is not available and we do not know the set of countries he uses, we will do robustness tests creating our own dataset, in which we will reproduce his results with his variables, but also run regressions making changes to address other flaws in his study that are listed below.

First, the variables he uses are inadequate for India especially and biased in favour of his result. Credit growth was very low after 2011 because of NPAs in banks and a macroeconomic policy squeeze. India's credit/GDP ratio has always been relatively low. As a major oil importer, both India's imports and exports are vulnerable to oil price crashes such as occurred in 2014. India's growth story has not been an export led growth story. Export and import are tightly linked since it is hard for India to finance a large current account deficit. He presents results with and without electricity consumption because he says the governments conscious electrification drive loads the results against finding India to be an outlier. But the variables he uses loads the results towards finding India to be an outlier.

Moreover, AS measures exports and imports in dollars when domestic currency is the relevant unit for measuring domestic output ${ }^{3}$. Using values in USD unnecessarily brings exchange rate volatility in explanatory variables. In the level regression also we should use local currency values, even if it amounts to different currency unit across countries,

\footnotetext{
${ }^{3}$ Every country provides estimates of GDP in their local currency.
} 
because our objective is to look for within variation of this relationship, which is going to be better captured if we use local currency. The fixed effects panel regression is a within estimator.

Second, other variables useful to predict growth such as government final consumption and labor force growth are also available independently of government statistical agencies but were not used. Government expenditure multipliers often exceed unity. Given the time period of the study includes the global financial crisis during which fiscal stimulus was the norm, leaving out government final consumption expenditure is puzzling. Endogeniety of government consumption expenditure can not be a reason because other variables are also endogenous in his regression.

India has favourable demographics, while decline in working age population is causing economic stagnation in many countries. In the long run, growth is dependent on the growth of labour force (Bloom and Finlay, 2009). In his paper, the regression is not on per capita growth but growth of GDP and therefore growth in labour force is an important variable. Thus there is omitted variable bias in his framework that should have been avoided.

Third, in his framework any structural change, which leads to less reliance on external sector for growth would be attributed as overestimation/underestimation. He notices this for China but sets it aside arguing the Chinese have a long history of overestimating GDP.

Fourth, although he repeats his regression for different types of country sets classified by income, oil export shares etc., he does not use a set of countries with the same dominance of the service sector that India has. Since this may be the deeper reason for India's relative growth differences it should be controlled for. We will reproduce the results using a subset of such countries.

Fifth, he neglects or assumes productivity growth differences to be constant across countries, which is inadequate in a growth regression, and again unfair to India whose 
productivity growth differential was rising in this period. We will control for it to some extent by including lag of GDP in our growth regression.

We get our data from the World Bank as AS does. But he does not use electricity consumption data from World Bank because WDI does not have electricity consumption from 2015 onwards. We do not have access to the electricity data used by AS. But he claims the use of electricity would increase the predicted growth of India ${ }^{4}$ so the calculated overestimation would be less. He therefore estimates his regressions with and without use of electricity consumption. The main result of the paper does not depend upon this variable. So we do our regressions without electricity. If we can refute the claim by AS without electricity then we would certainly be able to refute it with electricity.

Our regression results suggest that growth of export, import and private credit were not able to predict growth in India before 2011 too. One can see this in two ways. These variables give a predicted value and if the actual value is higher than that, then it could be overestimation by CSO or underestimation by these indicators. The central point of AS thesis is that these indicators were not underestimating growth before 2011 and therefore they ought not to underestimate post 2011. We find that these indicators underestimated growth even before 2011. The best plausible specification (panel regression in growth) suggest that the underestimation before 2011 was even higher than post 2011. Therefore, if these indicators were underestimating growth before, we do not have any reason to believe that they should not be underestimating post 2011.

Most importantly, if we use these regressions to predict growth in other countries in our sample post 2011 (akin to giving a false treatment), then almost half of them are either underestimating or overestimating growth. But the exogenous variation was for India only (true treatment as per AS). The overestimation in many similar countries is much higher than in India. One cannot argue that all these countries are overestimating or underestimating growth. Therefore, this is not the right framework and conclusions drawn from it are baseless. There is no evidence whatsoever that Indian growth was

\footnotetext{
${ }^{4}$ India ran a massive electrification drive in the treatment period 2012-16.
} 
overestimated.

Section 3 reproduces the methodology from AS. Section 4 gives the empirical strategy used to invalidate the claim made in AS. Section 5 gives a brief description of data and is followed by falsification tests in section 6 . Section 7 give concluding remarks. Detailed tables are given in an Appendix.

\section{Methodology}

AS uses an impact evaluation regression design in which the treatment is the GDP estimation methodology change in India. The baseline cross-section regression is given by:

GrowthGDP $_{i}=\beta_{0}+\beta_{1}$ GrowthExport $_{i}+\beta_{2}$ GrowthImport $_{i}+\beta_{3}$ GrowthCredit $_{i}+\beta_{4}$ India $+\epsilon_{i}$

where $i$ is country. Two separate regressions are estimated using average growth of 2002-11 and 2012-16. If the India dummy comes out high and significant in the second period i.e. 2012-16, that implies these indicators fall short in predicting growth in the second period and there is overestimation in growth as argued in his paper. Instead of doing split sample regression, one can do one single regression in a difference in difference framework:

$$
\begin{aligned}
\text { GrowthGDP }_{i} & =\beta_{0}+\beta_{1} \text { GrowthExport }_{i}+\beta_{2} \text { GrowthImport }_{i}+\beta_{3} \text { GrowthCredit }_{i} \\
& +\beta_{4} \text { India }_{+}+\beta_{5} T+\beta_{6} \text { GrowthExport }_{i} \times T+\beta_{7} \text { GrowthImport }_{i} \times T \\
+ & \beta_{8} \text { GrowthCredit }_{i} \times T+\beta_{9} \text { India } \times T+\epsilon_{i t}
\end{aligned}
$$

The relationship between the indicators and growth is allowed to vary across the two periods as reflected in the interaction of each of these indicators with the second period time dummy $T$. The dummy is zero and one. It measures the average annual overestimation in growth because we are doing regressions with averages. We have two observations for each country, pre-treatment and post-treatment. The coefficient of interest is $\beta_{9}$, namely, 
whether Indian growth is over-estimated in the second period relative to the first. This regression is slightly different from the first one as it controls for India fixed effects and time fixed effects. The panel version of the same is given below (we do not have country and time dummy as before because they are now part of country and time fixed effects $)^{5}$ :

$$
\begin{aligned}
\text { GrowthGDP }_{i t} & =\beta_{0}+\beta_{1} \text { GrowthExport }_{i t}+\beta_{2} \text { GrowthImport }_{i t}+\beta_{3} \text { GrowthCredit }_{i t} \\
& +\beta_{4} \text { GrowthExport }_{i t} \times T+\beta_{5} \text { GrowthImport }_{i} \times T \\
+ & \beta_{6} \text { GrowthCredit }_{i t} \times T+\beta_{7} \text { India } \times T+\theta_{i}+\gamma_{t}+\epsilon_{i t}
\end{aligned}
$$

Where $\theta_{i}$ is country fixed effects and $\gamma_{t}$ is time fixed effects. Since we control for time and country fixed effects these regressions are better than the regressions above. This captures the unobserved heterogeneity across countries, which is time invariant. This regression also suffers from omitted variable bias and omission of time varying unobserved effects such as productivity. But we will ignore these biases as AS does, since our objective is not primarily to criticize his methodology, but to show there is no evidence of overestimation even using his methodology (thus invalidating his empirical design). Again the coefficient of interest is $\beta_{7}$, namely, whether Indian growth is over-estimated in the second period relative to the first. In this regression the treatment dummy consists of zero and one (zero for comparison period and one for treatment period). The coefficient $\beta_{7}$ gives the annual average overestimation in growth. Instead of doing a panel regression in growth, AS does a panel regression in levels as given below:

$$
\begin{aligned}
\log \left(G D P_{i t}\right) & =\beta_{0}+\log \left(\text { Export }_{i t}\right)+\beta_{2} \log \left(\text { Import }_{i t}\right)+\beta_{3} \log \left(\text { Credit }_{i t}\right)+\beta_{4} \log \left(\text { Export }_{i t}\right) \times T \\
& +\beta_{5} \log \left(\text { Import }_{i t}\right) \times T+\beta_{6} \log \left(\text { Credit }_{i t}\right) \times T+\beta_{7} \text { India } \times T+\theta_{i}+\gamma_{t}+\epsilon_{i t}
\end{aligned}
$$

Here again the coefficient of interest is $\beta_{7}$, namely, whether Indian GDP is over-estimated in the second period relative to the first. The panel regression in levels is problematic

\footnotetext{
${ }^{5}$ Ideally growth regression should be done in per capital income growth which has theoretical underpinnings based on convergence hypothesis. Our regression specification is completely a-theoretical. But still our growth specification is better than level specification of AS. We will control for lag of GDP in one specification too. This regression should not be misunderstood as regressions done for test for convergence as convergence regressions are in per capita terms
} 
due to the possibility of a unit root. Harris-Tzavalis test for panel unit root suggest that GDP has a unit root. We prefer Harris-Tzavalis over test over Levin-Lin-Chu test because Levin-Lin-Chu test is not well suited to datasets with a large number of panels and relatively few time periods which is the case here. Moreover, we believe that since the issue is related to the growth rate rather than level, the growth regression should be more efficient as it does not suffer from the problem of unit root.

\section{What Will Invalidate Mr. Subramanian's Claim?}

\subsection{Cross Sectional Regressions}

First, in cross sectional regressions the India dummy coefficient for after 2011 is important. If we change the definition of treatment period (false treatment) and make it after 2008 ? We do not expect the coefficient of India dummy to become insignificant because after 2008 it still contains the overestimation post 2011 if there is any. But the coefficient of India dummy should reduce because the average overestimation would be less now. The overestimation being estimated is yearly average overestimation so if the growth was estimated correctly before 2011, then the coefficient from this regression should be lower as the same amount of overestimation is being spread over more years now. The lower coefficient is only a necessary condition and not a sufficient one. There is a possibility that overestimation was there in earlier period too but the amount of overestimation was less, that would also give a lower coefficient. But in no circumstances the India dummy coefficient should be higher if we change the treatment to an earlier period if the true treatment came later. A higher coefficient obtained from lowering the treatment time will invalidate AS claim.

Second, India dummy coefficient should not turn out to be significant for any split sample regression which does not contain post 2011 time period because there was no change in estimation during these times. But if we get significant and high India dummy, that will imply that this relation was not able to predict growth in India before 2011 also. 
This is similar to testing parallel trend assumption. AS placebo regression suggests India was almost an outlier during the period 2007-11 but AS choose to ignore it.

Third, another falsification test is giving false treatment to other countries. If a significant number of countries turn out to be outliers, that will imply that this methodology is not the right one to predict growth and will invalidate the AS claim. AS finds China to be an outlier but rejects the result citing the reason that Chinese have a long history of overestimating growth. Another outlier is Ireland, but he argues this is because Ireland artificially recognises profit of US companies based in its jurisdiction. One can do these falsification tests in cross section regressions too but we will prefer the results from panel regressions as those have more information and controls for country fixed effects. In cross section there is a danger that these falsification tests may pick unobserved country fixed effects. In cross section we will do first two falsification test and in difference in difference regression the second falsification test. The second test covers the first too.

\subsection{Panel Regressions}

First, in panel regressions also the India dummy interacted with treatment dummy (post 2011) should decrease if we lower the treatment period, for example if we make it 2008. India dummy interacted with time is measuring the annual overestimation in growth rate. Lowering the cut point will not make it insignificant because it still has the overestimation post 2011, assuming that it has been overestimated. But this coefficient should decrease as argued above. Again lower coefficient is a necessary condition only. This is based on the assumption that we were measuring growth correctly till 2011 using the old methodology. An increase in the coefficient of India dummy interacted with treatment dummy (post 2011) will invalidate the AS claim.

Second, similar to the cross section regressions if we discard the data post 2011 and spilt the remaining time period into two using any arbitrary cut point then the coefficient of India dummy interacted with treatment dummy should not turn out to be significant. If it turns out to be significant then that would imply overestimation existed earlier also 
and cannot be attributed to the methodological change.

Third, similar to cross section regressions, if this framework is not able to predict growth of other countries in case of false treatment, then any implication drawn by using this framework to cast doubt on Indian GDP would be unfounded. Only one conclusion would be valid, this is not the right framework to predict growth. We will do second and third falsification tests in panel regressions.

\section{Data}

We take all data from the World Bank. AS drops all atypical (oil exporting, mired in conflict) countries as mentioned. The criterion for oil export is not mentioned in the paper. If one takes export by volume then many large economies will also fall in that list for example (US). We use oil rent as \% of GDP as our selection criterion. Any country having more than $20 \%$ of GDP coming from the oil rent is dropped from the sample. Remember these times had very high and low oil prices. As AS did, we also eliminate all countries mired in conflict (as mentioned on the World Bank site) and countries with population less than 1000000 . We drop countries with missing observations for any year during the estimation period as we are dealing with average in a few regressions and missing observations can bias results. We drop four outliers (Cambodia, Tajikistan, Ireland and Ukraine) as per AS. We use the Indian growth rate AS uses. Other countries growth rates are calculated from World Bank data. This gives us a list of 82 countries. We

also estimate the models dropping a few more small countries and countries not having a share of service sector in economy comparable to India (this gives us 62 countries). 


\section{Results: Falsification}

\subsection{Cross Sectional Regressions}

We estimate all regressions with two sets of countries (82 and 62). Here we discuss results obtained from the first set of countries. The second set is for robustness and gives the same results. One can see all these regression results in detail in the Appendix.

Cross sectional regression results are given in tables 6-9 in appendix. Here we reproduce the coefficient of interest. The India dummy coefficient for post 2011 treatment is 3.75 (table1) and is similar to (3.9) reported in AS with all countries. Bringing additional controsl such as government expenditure and labour force growth reduces this coefficient (table 2), implying AS overestimates the overestimation but that is not the main point. As we can see from table 1, Indian dummy coefficient during the period 2009-16 is greater than during 2012-16. This should not have happened if the growth was predicted well by these indicators before 2011 as argued in above section. This is the first falsification. AS did not do it. In other words the regression does not pass the smell test.

Table 1: India Dummy: Spilt Sample Cross Sectional Regressions, AS Variables

\begin{tabular}{ccccc}
\hline Treatment Period & $2012-16$ & $2009-16$ & $2006-11$ & $2006-10$ \\
Coefficient of India Dummy & $3.749 * * *$ & $4.061^{* * *}$ & $1.164^{* * *}$ & $1.910^{* * *}$ \\
\hline
\end{tabular}

Notes: For treatment 2006-10, data beyond 2010 is dropped and the comparison group is 200205. For treatment 2006-11, data beyond 2011 is dropped and the comparison group is 2002-05. $*, * *$ and $* * *$ denotes significance at 10,5 and 1 percent respectively.

Table 2: India Dummy: Spilt Sample Cross Sectional Regressions, Including Other Relevant Variables

\begin{tabular}{ccccc}
\hline Treatment Period & $2012-16$ & $2009-16$ & $2006-11$ & $2006-10$ \\
Coefficient of India Dummy & $3.462 * * *$ & $3.778^{* * *}$ & $1.599 * * *$ & $2.242 * * *$ \\
\hline
\end{tabular}

Notes: For treatment 2006-10, data beyond 2010 is dropped and the comparison group is 200205. For treatment 2006-11, data beyond 2011 is dropped and the comparison group is 2002-05. $*, * *$ and $* * *$ denotes significance at 10,5 and 1 percent respectively. 
As we can see from tables 1 and 2 above, India dummy coefficient was significant during 2006-11 and 2006-10 too. These regressions were done after discarding observations beyond 2011 and 2010. This is the second falsification. If these indicators were predicting Indian growth before 2011 and 2010, then India dummy coefficient should not have turned out to be significant. We would like to clarify that AS had this warning in his placebo but he chose to ignore it. The difference between Indian dummy post 2011 and between $2006-10$ is 1.2 . We can not quibble about the magnitude of overestimation in two time periods as that is not the main point. These regressions are cross sectional and do not control for heterogeneity among countries and have problems of omitted variables.

\subsection{Difference in Difference Regressions}

Table 3: India Dummy Interacted with Treatment: Difference in Difference Regressions

\begin{tabular}{ccccc}
\hline Treatment Period & $2012-16(!)$ & $2012-16$ & $2006-10(!)$ & $2006-10$ \\
Coefficient of India Dummy & $3.241^{* * *}$ & $2.767^{* * *}$ & $1.393^{*}$ & $2.424 * * *$ \\
\hline
\end{tabular}

Notes: For treatment 2006-10, data beyond 2010 is dropped and the comparison group is 2002-05. (!) in the column implies specification as in AS, other two gives the coefficient from specification with other relevant explanatory variables. ${ }^{*}, * *$ and ${ }^{* * *}$ denotes significance at 10,5 and 1 percent respectively.

Tables 10-11 in the Appendix give results from a difference in difference estimator. This is a better regression than the pure cross sectional regression above as this allows us to control for India and time fixed effects. But there is no control for heterogeneity across other countries. All other countries are similar. In table 3 we report the coefficients of India dummy interacted with treatment time from AS specification as well as specifications including other relevant variables. Growth was overestimated by $2.76 \%$ and $2.42 \%$ during the period $2012-16$ and $2006-10$. These numbers are very similar, implying growth was underestimated during 2006-10. Therefore the underestimation reported by this specification during 2012-16 does not say anything about impact of change in methodology. This falsifies the difference in difference regression in AS. AS did not do this falsification test too. Next we move to panel regression, which is the best 
plausible specification as it allows controls for heterogeniety across countries to some extent.

\subsection{Panel Regressions}

\subsubsection{Growth}

The cross sectional regressions are problematic as we do not have controls for country level heterogeneity ${ }^{6}$. A panel regression is better, as it will have more information and allow us to concentrate on the within variation between countries, which is our objective. But one should note the caution that countries grow at different rates based on their productivity growth. The country fixed effect allows us to have different productivity levels across countries but they remain fixed over time.

Table 4: India Dummy Interacted with Treatment: Panel Regressions in Growth, AS Variables

\begin{tabular}{cccc}
\hline Treatment Period & $2012-16$ & $2007-10$ & $2007-10(!)$ \\
Coefficient of India Dummy & $1.751^{* * *}$ & $2.280 * * *$ & $3.385 * * *$
\end{tabular}

Notes: For treatment 2007-10, data beyond 2010 is dropped and the comparison group is 2002-06. (!) denotes the estimate obtained after controlling for individual country crisis year dummy for year 2008 and year 2009. *,** and *** denotes significance at 10,5 and 1 percent respectively.

These panel regressions are given in tables 12-15 in the Appendix. Here in table 4 we report the coefficient of the India dummy from the AS specification. The panel regression significantly decreases the overestimation reported by cross sectional and difference in difference regressions. The overestimation is now higher for 2007-10 ${ }^{7}$, especially after controlling for country specific crisis dummy for the year 2008 and 2009, compared to 2012-16. AS also used this control and it is reasonable as the crisis affected different

\footnotetext{
${ }^{6}$ It is not correct that since growth is first difference of log level of GDP, it allows us to control for heterogeneity across countries.

${ }^{7}$ This holds for other periods such as $2006-10$ as well.
} 
countries in different ways. This is another falsification and makes the claim made in AS completely redundant. Controlling for lag GDP reduces the coefficient of India dummy in all panel growth regressions. This coefficient captures the difference between growth rate of India and other countries. Control for lag GDP allows us to control for expected differences in growth rate between India and comparison group because of differences in income to some extent. Level regression in AS does not allow for this possibility.

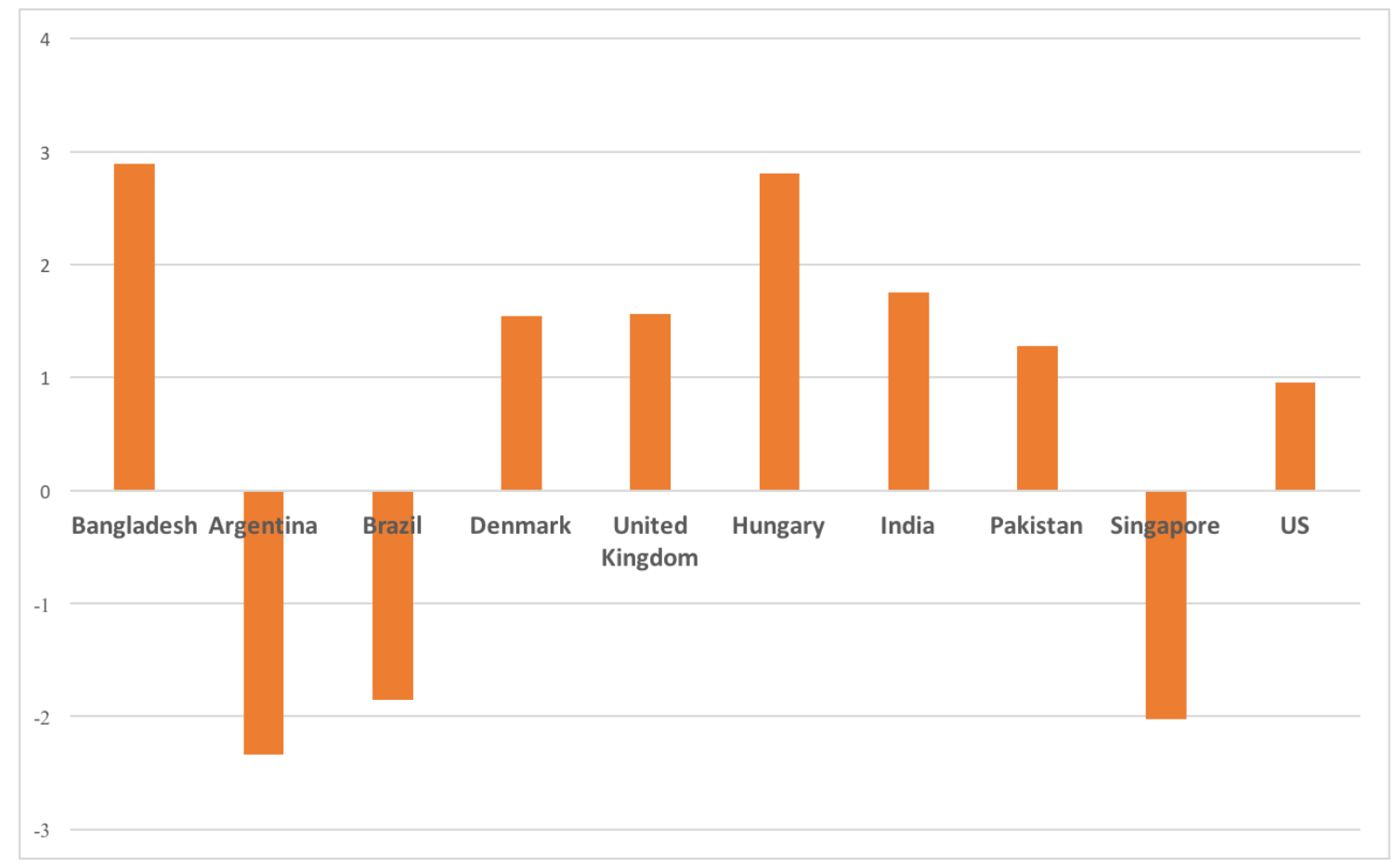

Figure 1: Overestimation/Underestimation as Per AS Methodology: Panel Regressions in Growth: Treatment Post 2011

What about the predicted growth in other countries? It is like giving false treatment to other countries. For AS they are the control group and therefore must not respond to treatment. As we can see from figure 1 overestimation is much higher in Hungry and Bangladesh in comparison to India. UK has a similar level of overestimation. Singapore is 
underestimating growth. We cannot say all these countries are wrongly estimating their growth, therefore, neither is India. This is our main result and a very significant falsification.

\subsubsection{Level}

AS did not do the panel regression in growth, only in levels. The latter is ill suited for this exercise, but we estimate the panel regression in levels also. The coefficients are reported in tables 16 and 17 in the Appendix. The coefficients of interest from the first set of level regression are reported in in table 5. The coefficient associate with India dummy is 0.149 (.203 in AS). With a better specification this coefficient is (0.128). But this panel regression also suggests that the GDP was overestimated during 2007-10 too ${ }^{8}$. If we include the country crisis dummy then the coefficient associated with India becomes (0.0690 and with a better specification it becomes 0.0847) during 2006-10.

Table 5: India Dummy Interacted with Treatment: Panel Regressions in Levels: AS Variables

\begin{tabular}{cccc}
\hline Treatment Period & $2012-16$ & $2007-10$ & $2007-10(!)$ \\
Coefficient of India Dummy & $0.149^{* * *}$ & $0.0553^{* * *}$ & $0.0690^{* * *}$ \\
\hline
\end{tabular}

Notes: For treatment 2007-10, data beyond 2010 is dropped and the comparison group is 2002-06. (!) denotes the estimate obtained after controlling for individual country crisis year dummy for year 2008 and year 2009. ${ }^{*}, * *$ and ${ }^{* * *}$ denotes significance at 10,5 and 1 percent respectively.

One can think of comparing these coefficients but that would be only about the predictive power of these variables over two time periods and will have nothing to do with the causal story about methodology as claimed in AS. These regressions overwhelmingly suggest that these indicators were not able to predict GDP in India before 2011 also. This is first falsification of level regression done by AS.

\footnotetext{
${ }^{8}$ This holds for other periods such as $2006-10$ as well.
} 


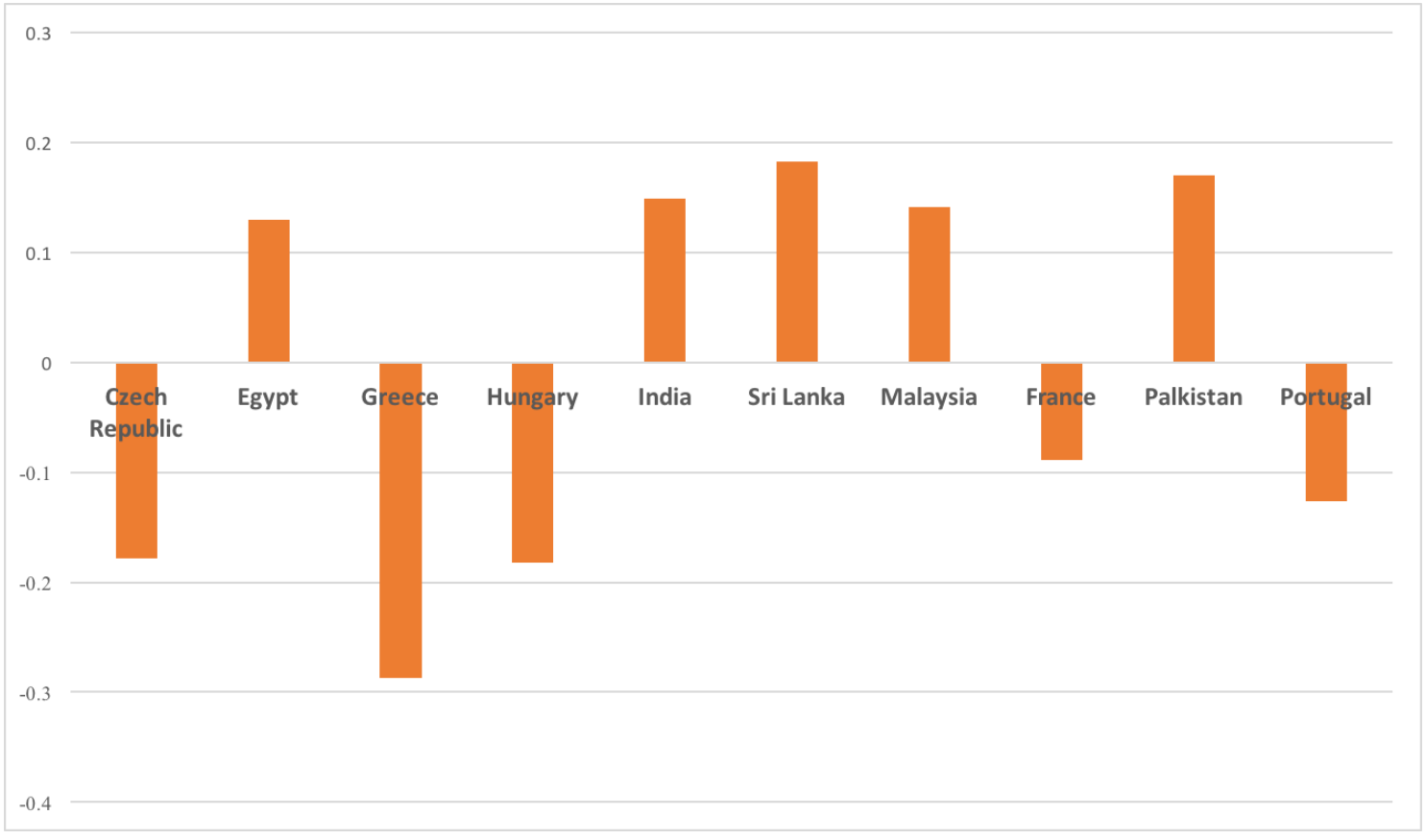

Figure 2: Overestimation/Underestimation as Per AS Methodology: Panel Regressions in Levels:Treatment Post 2011

The specification is not able to predict GDP in other countries post 2011 either. This is second falsification of level regression. If we believe the AS framework then Greece has been seriously underestimating GDP (figure 2). Sri Lanka has overestimation problem of higher magnitude than India.

\section{Concluding Remarks}

AS claims that export, import and private credit can predict Indian growth accurately before 2011 but not after 2011. According to him the predicted growth after 2011 is much lower than the actual growth reported by CSO and thus growth is being overestimated, after the methodological change in 2011-12. We show that these indicators were not predicting growth before 2011 either. Our best specification suggests these indicators were predicting much lower growth in the pre 2011 period compared to post 2011. Since these 
indicators could not predict growth before 2011, we do not have any reason to believe changes after 2011 have anything to do with GDP estimation methodology. Moreover, the AS methodology results in half of the world countries either overestimating or underestimating growth and GDP. Obviously all their national statistical agencies cannot be accused of overestimation/underestimation, and therefore the same logic applies to India.

The AS framework suffers from possibly all econometric issues related to regressions. There are problems because of omitted variable bias and endogeniety (imports may be caused by GDP). But we took this as a pure predictive regression (we do not think that AS is also claiming any causality apart from change in methodology) and tried to refute him in his framework only. There is overwhelming evidence that AS did not do required falsification tests. If these test would have been done then there was no claim of overestimation to begin with.

We agree with AS that policy, especially monetary policy, was tight post 2011. But he is incorrect when he argues higher estimated growth rates seriously misled policy. Policy-makers knew there was excess capacity in industry and investment growth had slumped, while it was the changing structure of the economy that raised the new growth estimates ${ }^{9}$. Yet they kept real interest rates higher than warranted, and imposed tight restraints on the budget, because they were focused on inflation in the newly introduced and strictly interpreted inflation targeting framework (Goyal and Kumar (2017, 2018, 2019). India's potential growth fell and it grew at average $7 \%$, when it should have grown above $8 \%$. But it did not grow at $4.5 \%$ as he alleges. It has long been noted that the Indian growth pattern is service-sector dominated. Therefore a manufacturing slowdown alone should not be expected to materially reduce growth rates.

The Indian statistical process is robust, independent and continually improving. More can and should be done to strengthen it and its advisory committees. More data should

\footnotetext{
${ }^{9}$ For example, the change from establishment to enterprise approach using financial MCA21 data relocated some high-growth services data from services to manufacturing, reducing the formers' rate of growth and increasing that of the latter. The IIP would not capture this change
} 
be transparently made available to encourage independent research but bringing in outside experts who do not understand the economy can be counter-productive. GST related data should certainly be used but it is part of the on-going migration to better data bases becoming available, to which there has been so much unnecessary objection. 


\section{Appendix}

Table 6: Cross Sectional Regressions: 82 Countries

\begin{tabular}{lcccccccc}
\hline \hline & $(2002-11)$ & $(2012-16)$ & $(2002-11)$ & $(2012-16)$ & $(2002-08)$ & $(2009-16)$ & $(2002-08)$ & $(2009-16)$ \\
& $A G$ & $A G$ & $A G$ & $A G$ & $A G$ & $A G$ & $A G$ & $A G$ \\
\hline AG Import & $0.208^{* *}$ & 0.0492 & $0.226^{* * *}$ & 0.00137 & 0.0817 & 0.100 & $0.124^{*}$ & -0.0140 \\
& $(0.031)$ & $(0.217)$ & $(0.000)$ & $(0.976)$ & $(0.270)$ & $(0.411)$ & $(0.098)$ & $(0.884)$ \\
AG Export & 0.137 & $0.0713^{*}$ & 0.0684 & $0.0706^{* * *}$ & $0.113^{* *}$ & -0.0316 & 0.0534 & 0.0664 \\
& $(0.127)$ & $(0.069)$ & $(0.181)$ & $(0.007)$ & $(0.041)$ & $(0.724)$ & $(0.340)$ & $(0.368)$ \\
AG Credit & $0.0760^{* *}$ & $0.253^{* * *}$ & $0.0711^{* *}$ & $0.178^{* * *}$ & $0.106^{* * *}$ & $0.287^{* * *}$ & $0.103^{* * *}$ & $0.145^{* * *}$ \\
& $(0.012)$ & $(0.000)$ & $(0.015)$ & $(0.000)$ & $(0.001)$ & $(0.000)$ & $(0.001)$ & $(0.001)$ \\
India & 0.508 & $3.749^{* * *}$ & 0.696 & $3.462^{* * *}$ & 0.609 & $4.061^{* * *}$ & 0.643 & $3.778^{* * *}$ \\
& $(0.305)$ & $(0.000)$ & $(0.129)$ & $(0.000)$ & $(0.228)$ & $(0.000)$ & $(0.226)$ & $(0.000)$ \\
AG Government Exp. & & & $0.153^{* * *}$ & $0.172^{* *}$ & & & $0.0805^{*}$ & $0.255^{* *}$ \\
& & & $(0.000)$ & $(0.012)$ & & & $(0.054)$ & $(0.014)$ \\
AG Labour Force & & & $0.432^{* * *}$ & $0.301^{* *}$ & & & $0.347^{* *}$ & $0.483^{* * *}$ \\
& & & $(0.000)$ & $(0.012)$ & & & $(0.010)$ & $(0.003)$ \\
Constant & $1.179^{* * *}$ & $1.473^{* * *}$ & 0.215 & $1.002^{* * *}$ & $2.046^{* * *}$ & $1.308^{* * *}$ & $1.242^{* *}$ & 0.466 \\
& $(0.001)$ & $(0.000)$ & $(0.457)$ & $(0.000)$ & $(0.000)$ & $(0.000)$ & $(0.013)$ & $(0.125)$ \\
\hline$R^{2}$ & 0.528 & 0.635 & 0.731 & 0.734 & 0.453 & 0.593 & 0.544 & 0.729 \\
Observations & 82 & 82 & 82 & 82 & 82 & 82 & 82 & 82 \\
\hline \hline
\end{tabular}

Notes: $A G$ is average growth rate of GDP over mentioned time period. AG Credit, AG Export, AG Import, AG Labour Force and AG Government Exp. are average growth rate of respective items. All items in local currency. ${ }^{*}, * *$ and ${ }^{* * *}$ denotes significance at 10,5 and 1 percent respectively. 
Table 7: Cross Sectional Regressions: 62 Countries

\begin{tabular}{|c|c|c|c|c|c|c|c|c|}
\hline & $\begin{array}{c}(2002-11) \\
\text { AG }\end{array}$ & $\begin{array}{c}(2012-16) \\
A G\end{array}$ & $\begin{array}{c}(2002-11) \\
\text { AG }\end{array}$ & $\begin{array}{c}(2012-16) \\
A G\end{array}$ & $\begin{array}{c}(2002-08) \\
A G\end{array}$ & $\begin{array}{c}(2009-16) \\
A G\end{array}$ & $\begin{array}{c}(2002-08) \\
\text { AG }\end{array}$ & $\begin{array}{c}(2009-16) \\
A G\end{array}$ \\
\hline AG Import & 0.166 & 0.0707 & $0.214^{* * *}$ & -0.00866 & 0.106 & -0.0282 & $0.146^{* *}$ & -0.147 \\
\hline & $(0.127)$ & $(0.156)$ & $(0.002)$ & $(0.901)$ & $(0.130)$ & $(0.778)$ & $(0.036)$ & $(0.133)$ \\
\hline AG Export & 0.142 & 0.0544 & 0.0360 & $0.103^{*}$ & 0.0999* & 0.0449 & 0.0399 & $0.126^{*}$ \\
\hline & $(0.124)$ & $(0.349)$ & $(0.493)$ & $(0.089)$ & $(0.078)$ & $(0.601)$ & $(0.472)$ & $(0.064)$ \\
\hline AG Credit & $\begin{array}{c}0.0710^{* *} \\
(0.037)\end{array}$ & $\begin{array}{c}0.243^{* * * *} \\
(0.000)\end{array}$ & $\begin{array}{c}0.0766^{* *} \\
(0.034)\end{array}$ & $\begin{array}{c}0.174^{* * * *} \\
(0.000)\end{array}$ & $\begin{array}{c}0.0808^{* * *} \\
(0.002)\end{array}$ & $\begin{array}{c}0.311^{* * *} \\
(0.000)\end{array}$ & $\begin{array}{c}0.0868^{* * *} \\
(0.005)\end{array}$ & $\begin{array}{c}0.175^{* * *} \\
(0.000)\end{array}$ \\
\hline India & $\begin{array}{c}0.756 \\
(0.189)\end{array}$ & $\begin{array}{c}3.778^{* * * *} \\
(0.000)\end{array}$ & $\begin{array}{l}1.040^{* *} \\
(0.035)\end{array}$ & $\begin{array}{c}3.418^{* * *} \\
(0.000)\end{array}$ & $\begin{array}{c}0.600 \\
(0.147)\end{array}$ & $\begin{array}{c}3.801^{* * *} \\
(0.000)\end{array}$ & $\begin{array}{c}0.697^{*} \\
(0.089)\end{array}$ & $\begin{array}{c}3.383^{* * *} \\
(0.000)\end{array}$ \\
\hline AG Government Exp. & & & $\begin{array}{c}0.161^{* * *} \\
(0.000)\end{array}$ & $\begin{array}{l}0.170^{*} \\
(0.061)\end{array}$ & & & $\begin{array}{c}0.0692^{* *} \\
(0.029)\end{array}$ & $\begin{array}{c}0.328^{* * *} \\
(0.003)\end{array}$ \\
\hline AG Labour Force & & & $\begin{array}{c}0.468^{* * *} \\
(0.001)\end{array}$ & $\begin{array}{l}0.230^{*} \\
(0.094)\end{array}$ & & & $\begin{array}{l}0.379^{* *} \\
(0.012)\end{array}$ & $\begin{array}{l}0.346^{* *} \\
(0.013)\end{array}$ \\
\hline Constant & $\begin{array}{c}1.550^{* * *} \\
(0.001)\end{array}$ & $\begin{array}{c}1.568^{* * *} \\
(0.000)\end{array}$ & $\begin{array}{c}0.342 \\
(0.351)\end{array}$ & $\begin{array}{c}1.078^{* * *} \\
(0.000)\end{array}$ & $\begin{array}{c}2.208^{* * *} \\
(0.000)\end{array}$ & $\begin{array}{c}1.450^{* * *} \\
(0.000)\end{array}$ & $\begin{array}{l}1.286^{* *} \\
(0.012)\end{array}$ & $\begin{array}{l}0.529^{*} \\
(0.083)\end{array}$ \\
\hline$R^{2}$ & 0.474 & 0.686 & 0.729 & 0.744 & 0.471 & 0.663 & 0.589 & 0.787 \\
\hline Observations & 62 & 62 & 62 & 62 & 62 & 62 & 62 & 62 \\
\hline
\end{tabular}

Notes: $A G$ is average growth rate of GDP over mentioned time period. AG Credit, AG Export, AG Import, AG Labour Force and AG Government Exp. are average growth rate of respective items. All items in local currency. $*, * *$ and $* * *$ denotes significance at 10,5 and 1 percent respectively. 
Table 8: Cross Sectional Regressions: 82 Countries

\begin{tabular}{lcccccc}
\hline \hline & $(2002-05)$ & $(2006-11)$ & $(2002-05)$ & $(2006-11)$ & $(2006-10)$ & $(2006-10)$ \\
& $\mathrm{AG}$ & $\mathrm{AG}$ & $\mathrm{AG}$ & $\mathrm{AG}$ & $\mathrm{AG}$ & $\mathrm{AG}$ \\
\hline AG Import & 0.0342 & $0.236^{* * *}$ & 0.0466 & $0.194^{* * *}$ & $0.243^{* * *}$ & $0.203^{* * *}$ \\
& $(0.515)$ & $(0.000)$ & $(0.428)$ & $(0.000)$ & $(0.000)$ & $(0.000)$ \\
AG Export & $0.209^{* * *}$ & $0.194^{* * *}$ & $0.172^{* * *}$ & $0.148^{* * *}$ & $0.143^{* *}$ & 0.0827 \\
& $(0.000)$ & $(0.004)$ & $(0.000)$ & $(0.004)$ & $(0.033)$ & $(0.124)$ \\
AG Credit & $0.0786^{* * *}$ & $0.0766^{* * *}$ & $0.0762^{* * *}$ & $0.0716^{* * *}$ & $0.0614^{* *}$ & $0.0657^{* *}$ \\
& $(0.000)$ & $(0.002)$ & $(0.000)$ & $(0.000)$ & $(0.022)$ & $(0.015)$ \\
India & -0.327 & $1.164^{* *}$ & -0.183 & $1.599^{* * *}$ & $1.910^{* * *}$ & $2.242^{* * *}$ \\
& $(0.624)$ & $(0.010)$ & $(0.797)$ & $(0.003)$ & $(0.000)$ & $(0.000)$ \\
AG Government Exp. & & & $0.105^{* * *}$ & $0.186^{* * *}$ & & $0.199^{* * *}$ \\
& & & $(0.000)$ & $(0.003)$ & & $(0.002)$ \\
AG Labour Force & & & 0.180 & $0.487^{* * *}$ & & $0.449^{* * *}$ \\
& & & $(0.140)$ & $(0.001)$ & & $(0.003)$ \\
Constant & $1.802^{* * *}$ & $0.810^{* *}$ & $1.307^{* * *}$ & -0.198 & $1.285^{* * *}$ & 0.133 \\
& $(0.000)$ & $(0.039)$ & $(0.003)$ & $(0.483)$ & $(0.001)$ & $(0.687)$ \\
\hline$R^{2}$ & 0.531 & 0.549 & 0.621 & 0.766 & 0.460 & 0.679 \\
Observations & 82 & 82 & 82 & 82 & 82 & 82 \\
\hline \hline
\end{tabular}

Notes: AG is average growth rate of GDP over mentioned time period. AG Credit, AG Export, AG Import, AG Labour Force and AG Government Exp. are average growth rate of respective items. All items in local currency. Column header denotes treatment time period. For treatment 2006-10, data beyond 2010 is dropped and the comparison group is 2002-05. For treatment 2006-11, data beyond 2011 is dropped and the comparison group is 2002-05. *,** and *** denotes significance at 10, 5 and 1 percent respectively. 
Table 9: Cross Sectional Regressions: 62 Countries

\begin{tabular}{lcccccc}
\hline \hline & $(2002-05)$ & $(2006-11)$ & $(2002-05)$ & $(2006-11)$ & $(2006-10)$ & $(2006-10)$ \\
& $\mathrm{AG}$ & $\mathrm{AG}$ & $\mathrm{AG}$ & $\mathrm{AG}$ & $\mathrm{AG}$ & $\mathrm{AG}$ \\
\hline AG Import & 0.0534 & $0.219^{* * *}$ & 0.0516 & $0.209^{* * *}$ & $0.202^{* * *}$ & $0.210^{* * *}$ \\
& $(0.388)$ & $(0.003)$ & $(0.420)$ & $(0.000)$ & $(0.003)$ & $(0.000)$ \\
AG Export & $0.141^{* *}$ & $0.156^{* *}$ & $0.106^{* *}$ & 0.0822 & $0.148^{*}$ & 0.0614 \\
& $(0.010)$ & $(0.044)$ & $(0.028)$ & $(0.102)$ & $(0.054)$ & $(0.312)$ \\
AG Credit & $0.0773^{* * *}$ & $0.0807^{* *}$ & $0.0806^{* * *}$ & $0.0751^{* * *}$ & $0.0673^{*}$ & $0.0699^{*}$ \\
& $(0.001)$ & $(0.016)$ & $(0.001)$ & $(0.009)$ & $(0.057)$ & $(0.074)$ \\
India & 0.260 & $1.353^{* *}$ & 0.500 & $1.696^{* * *}$ & $1.982^{* * *}$ & $2.192^{* * *}$ \\
& $(0.679)$ & $(0.012)$ & $(0.461)$ & $(0.003)$ & $(0.001)$ & $(0.000)$ \\
AG Government Exp. & & & $0.0980^{* * *}$ & $0.219^{* * *}$ & & $0.223^{* * *}$ \\
& & & $(0.000)$ & $(0.001)$ & & $(0.002)$ \\
AG Labour Force & & & $0.216^{* *}$ & $0.492^{* * *}$ & & $0.506^{* * *}$ \\
& & & $(0.047)$ & $(0.005)$ & & $(0.004)$ \\
Constant & $2.175^{* * *}$ & $1.222^{* * *}$ & $1.651^{* * *}$ & -0.0917 & $1.604^{* * *}$ & 0.0381 \\
& $(0.000)$ & $(0.008)$ & $(0.001)$ & $(0.767)$ & $(0.001)$ & $(0.921)$ \\
\hline$R^{2}$ & 0.484 & 0.499 & 0.610 & 0.768 & 0.413 & 0.680 \\
Observations & 62 & 62 & 62 & 62 & 62 & 62 \\
\hline \hline
\end{tabular}

Notes: AG is average growth rate of GDP over mentioned time period. AG Credit, AG Export, AG Import, AG Labour Force and AG Government Exp. are average growth rate of respective items. All items in local currency. Column header denotes treatment time period. For treatment 2006-10, data beyond 2010 is dropped and the comparison group is 2002-05. For treatment 2006-11, data beyond 2011 is dropped and the comparison group is 2002-05. *,** and *** denotes significance at 10, 5 and 1 percent respectively. 
Table 10: Difference In Difference Regressions: 82 Countries

\begin{tabular}{lcccc}
\hline \hline & $(2012-16)$ & $(2012-16)$ & $(2006-10)$ & $(2006-10)$ \\
& $\mathrm{AG}$ & $\mathrm{AG}$ & $\mathrm{AG}$ & $\mathrm{AG}$ \\
\hline AG Import & $0.208^{* *}$ & $0.226^{* * *}$ & 0.0342 & 0.0466 \\
& $(0.030)$ & $(0.000)$ & $(0.514)$ & $(0.427)$ \\
AG Export & 0.137 & 0.0684 & $0.209^{* * *}$ & $0.172^{* * *}$ \\
& $(0.125)$ & $(0.179)$ & $(0.000)$ & $(0.000)$ \\
AG Credit & $0.0760^{* *}$ & $0.0711^{* *}$ & $0.0786^{* * *}$ & $0.0762^{* * *}$ \\
& $(0.011)$ & $(0.014)$ & $(0.000)$ & $(0.000)$ \\
dummy=1 × India=1 & $3.241^{* * *}$ & $2.767^{* * *}$ & $1.393^{*}$ & $2.424^{* * *}$ \\
& $(0.000)$ & $(0.000)$ & $(0.076)$ & $(0.007)$ \\
dummy=1 $\times$ AG Import & -0.158 & $-0.225^{* * *}$ & $0.209^{* * *}$ & $0.156^{* *}$ \\
& $(0.125)$ & $(0.003)$ & $(0.009)$ & $(0.034)$ \\
dummy=1 $\times$ AG Export & -0.0657 & 0.00213 & -0.0662 & -0.0896 \\
& $(0.499)$ & $(0.970)$ & $(0.425)$ & $(0.206)$ \\
dummy=1 $\times$ AG Credit & $0.177^{* * *}$ & $0.107^{* * *}$ & -0.0171 & -0.0105 \\
& $(0.000)$ & $(0.007)$ & $(0.596)$ & $(0.746)$ \\
AG Government Exp. & & $0.153^{* * *}$ & & $0.105^{* * *}$ \\
& & $(0.000)$ & & $(0.000)$ \\
AG Labour Force & & $0.432^{* * *}$ & & 0.180 \\
& & $(0.000)$ & & $(0.138)$ \\
dummy=1 $\times$ AG Government Exp. & & 0.0193 & & 0.0936 \\
& & $(0.793)$ & & $(0.151)$ \\
dummy=1 $\times$ AG Labour Force & & -0.130 & & 0.269 \\
& & $(0.420)$ & & $(0.156)$ \\
\hline$R^{2}$ & 0.601 & 0.745 & 0.505 & 0.654 \\
Observations & 164 & 164 & 164 & 164 \\
\hline \hline
\end{tabular}

Notes: AG is average growth rate of GDP over mentioned time period. AG Credit, AG Export, AG Import, AG Labour Force and AG Government Exp. are average growth rate of respective items. All items in local currency. dummy $=1$ is the time dummy for the period mentioned in the column header. It is basically 0,1 as there are only two observations each country. This denotes the treatment dummy for the mentioned time period. For treatment 2006-10, data beyond 2010 is dropped and the comparison group is 2002-05. ${ }^{*}, * *$ and $* * *$ denotes significance at 10,5 and 1 percent respectively. 
Table 11: Difference In Difference Regressions: 62 Countries

\begin{tabular}{lcccc}
\hline \hline & $(2012-16)$ & $(2012-16)$ & $(2006-10)$ & $(2006-10)$ \\
& $\mathrm{AG}$ & $\mathrm{AG}$ & $\mathrm{AG}$ & $\mathrm{AG}$ \\
\hline AG Import & 0.166 & $0.214^{* * *}$ & 0.0534 & 0.0516 \\
& $(0.124)$ & $(0.002)$ & $(0.386)$ & $(0.419)$ \\
AG Export & 0.142 & 0.0360 & $0.141^{* * *}$ & $0.106^{* *}$ \\
& $(0.122)$ & $(0.491)$ & $(0.009)$ & $(0.026)$ \\
AG Credit & $0.0710^{* *}$ & $0.0766^{* *}$ & $0.0773^{* * *}$ & $0.0806^{* * *}$ \\
& $(0.034)$ & $(0.032)$ & $(0.001)$ & $(0.000)$ \\
dummy=1 × India=1 & $3.022^{* * *}$ & $2.378^{* * *}$ & 1.411 & $1.692^{*}$ \\
& $(0.000)$ & $(0.000)$ & $(0.126)$ & $(0.060)$ \\
dummy=1 $\times$ AG Import & -0.0958 & $-0.223^{* *}$ & $0.149^{*}$ & $0.158^{*}$ \\
& $(0.420)$ & $(0.023)$ & $(0.096)$ & $(0.059)$ \\
dummy=1 $\times$ AG Export & -0.0877 & 0.0672 & 0.00666 & -0.0447 \\
& $(0.418)$ & $(0.398)$ & $(0.942)$ & $(0.560)$ \\
dummy=1 $\times$ AG Credit & $0.172^{* * *}$ & $0.0975^{*}$ & -0.0101 & -0.0107 \\
& $(0.000)$ & $(0.063)$ & $(0.806)$ & $(0.810)$ \\
AG Government Exp. & & $0.161^{* * *}$ & & $0.0980^{* * *}$ \\
& & $(0.000)$ & & $(0.000)$ \\
AG Labour Force & & $0.468^{* * *}$ & & $0.216^{* *}$ \\
& & $(0.001)$ & & $(0.044)$ \\
dummy=1 $\times$ AG Government Exp. & & 0.00907 & & $0.125^{*}$ \\
& & $(0.925)$ & & $(0.084)$ \\
dummy=1 $\times$ AG Labour Force & & -0.238 & & 0.290 \\
& & $(0.216)$ & & $(0.145)$ \\
\hline$R^{2}$ & 0.604 & 0.749 & 0.448 & 0.650 \\
Observations & 124 & 124 & 124 & 124 \\
\hline \hline
\end{tabular}

Notes: AG is average growth rate of GDP over mentioned time period. AG Credit, AG Export, AG Import, AG Labour Force and AG Government Exp. are average growth rate of respective items. All items in local currency. dummy $=1$ is the time dummy for the period mentioned in the column header. It is basically 0,1 as there are only two observations each country. This denotes the treatment dummy for the mentioned time period. For treatment 2006-10, data beyond 2010 is dropped and the comparison group is 2002-05. ${ }^{*}, * *$ and $* * *$ denotes significance at 10,5 and 1 percent respectively. 
Table 12: Panel Regressions In Growth: 82 Countries

\begin{tabular}{lcccccc}
\hline \hline & $(2012-16)$ & $(2012-16)$ & $(2012-16)$ & $(2007-10)$ & $(2007-10)$ & $(2007-10)$ \\
& $G$ & $G$ & $G$ & $G$ & $G$ & $G$ \\
\hline G Import & $0.0978^{* * *}$ & $0.102^{* * *}$ & $0.0799^{* * *}$ & $0.100^{* * *}$ & $0.113^{* * *}$ & $0.0569^{* *}$ \\
& $(0.000)$ & $(0.000)$ & $(0.000)$ & $(0.005)$ & $(0.000)$ & $(0.014)$ \\
G Export & 0.0332 & 0.0318 & 0.00856 & 0.0160 & 0.00953 & -0.0296 \\
& $(0.157)$ & $(0.151)$ & $(0.636)$ & $(0.693)$ & $(0.803)$ & $(0.207)$ \\
G Credit & $0.0402^{* * *}$ & $0.0382^{* * *}$ & $0.0379^{* * *}$ & $0.0406^{* * *}$ & $0.0381^{* * *}$ & $0.0327^{* * *}$ \\
& $(0.000)$ & $(0.001)$ & $(0.000)$ & $(0.003)$ & $(0.003)$ & $(0.004)$ \\
DG Import & 0.00837 & -0.00782 & 0.00453 & 0.0145 & -0.00812 & $0.0473^{* *}$ \\
& $(0.778)$ & $(0.786)$ & $(0.865)$ & $(0.692)$ & $(0.815)$ & $(0.048)$ \\
DG Export & $0.0850^{* *}$ & $0.0933^{* * *}$ & $0.122^{* * *}$ & 0.0195 & 0.0301 & $0.0611^{* *}$ \\
& $(0.020)$ & $(0.008)$ & $(0.002)$ & $(0.670)$ & $(0.507)$ & $(0.027)$ \\
DG Credit & $0.0307^{*}$ & $0.0301^{*}$ & $0.0373^{* *}$ & -0.0266 & -0.0219 & -0.00951 \\
& $(0.069)$ & $(0.093)$ & $(0.031)$ & $(0.119)$ & $(0.171)$ & $(0.573)$ \\
India Post & $1.751^{* * *}$ & $1.746^{* * *}$ & $1.626^{* * *}$ & $2.280^{* * *}$ & $2.184^{* * *}$ & $1.198^{* *}$ \\
& $(0.000)$ & $(0.000)$ & $(0.000)$ & $(0.000)$ & $(0.001)$ & $(0.019)$ \\
G Government Exp. & & $0.0460^{* *}$ & $0.0278^{* *}$ & & $0.0447^{* * *}$ & $0.0152^{*}$ \\
& & $(0.016)$ & $(0.039)$ & & $(0.006)$ & $(0.055)$ \\
G Labour Force & & 0.0414 & -0.00356 & & 0.00187 & -0.0868 \\
& & $(0.553)$ & $(0.959)$ & & $(0.983)$ & $(0.345)$ \\
DG Government Exp. & & 0.0111 & 0.0380 & & 0.00372 & 0.0274 \\
& & $(0.821)$ & $(0.292)$ & & $(0.933)$ & $(0.576)$ \\
DG Labour Force & & 0.00504 & 0.0938 & & 0.0899 & $0.186^{*}$ \\
& & $(0.954)$ & $(0.312)$ & & $(0.379)$ & $(0.093)$ \\
L.IGDP & & & $-3.478^{* * *}$ & & & $-6.664^{*}$ \\
& & & $(0.010)$ & & & $(0.073)$ \\
Constant & $2.656^{* * *}$ & $2.429^{* * *}$ & $99.65^{* * *}$ & $2.718^{* * *}$ & $2.546^{* * *}$ & $188.9^{*}$ \\
& $(0.000)$ & $(0.000)$ & $(0.008)$ & $(0.000)$ & $(0.000)$ & $(0.068)$ \\
\hline$R^{2}$ & 0.474 & 0.489 & 0.510 & 0.502 & 0.518 & 0.555 \\
Observations & 1230 & 1230 & 1148 & 738 & 738 & 656 \\
\hline \hline
\end{tabular}

Notes: G is growth rate of GDP. G Credit, G Export, G Import, G Labour Force and G Government Exp. are growth rate of respective items. With $D$ prefix they denote interaction with treatment time dummy. Treatment time period is mentioned in the column header. For treatment 2007-10, observations beyond 2010 are dropped and the comparison group is 2002-06. L.IGDP is lag of natural log of GDP. India Post is the interaction of India (country dummy) with post dummy (years indicated by column header). All items in local currency. ${ }^{*}, * *$ and *** denotes significance at 10,5 and 1 percent respectively. 
Table 13: Panel Regressions In Growth: With Country Crisis Dummy: 82 Countries

\begin{tabular}{lccc}
\hline \hline & $(2007-10:$ Crisis Dummy) & $(2007-10:$ Crisis Dummy) & $(2007-10:$ Crisis Dummy) \\
& $G$ & $G$ & $G$ \\
\hline G Import & $0.107^{* * *}$ & $0.122^{* * *}$ & $0.0684^{* * *}$ \\
& $(0.008)$ & $(0.000)$ & $(0.006)$ \\
G Export & 0.0132 & 0.00631 & -0.0204 \\
& $(0.772)$ & $(0.879)$ & $(0.388)$ \\
G Credit & $0.0396^{* *}$ & $0.0368^{* *}$ & $0.0360^{* * *}$ \\
& $(0.016)$ & $(0.016)$ & $(0.008)$ \\
DG Import & 0.0127 & -0.0107 & 0.0408 \\
& $(0.758)$ & $(0.796)$ & $(0.257)$ \\
DG Export & -0.0115 & -0.0000685 & 0.0181 \\
& $(0.839)$ & $(0.999)$ & $(0.696)$ \\
DG Credit & $-0.0536^{* *}$ & $-0.0508^{* *}$ & $-0.0437^{*}$ \\
& $(0.025)$ & $(0.035)$ & $(0.099)$ \\
India Post & $3.385^{* * *}$ & $3.463^{* * *}$ & $2.335^{* * *}$ \\
& $(0.000)$ & $(0.000)$ & $(0.000)$ \\
G Government Exp. & & $0.0522^{* * *}$ & $0.0276^{* * *}$ \\
& & $(0.003)$ & $(0.003)$ \\
G Labour Force & & 0.0824 & 0.0365 \\
& & $(0.415)$ & $(0.685)$ \\
DG Government Exp. & & -0.0137 & -0.00901 \\
& & $(0.594)$ & $(0.740)$ \\
DG Labour Force & & 0.0250 & 0.0686 \\
& & $(0.839)$ & $(0.569)$ \\
L.IGDP & & & -2.691 \\
& & $-4.541^{* * *}$ & $(0.300)$ \\
Constant & & $(0.000)$ & 71.18 \\
& & 0.726 & $(0.324)$ \\
\hline$R^{2}$ & 738 & 0.801 \\
Observations & $-4.020^{* * *}$ & 656 \\
\hline \hline
\end{tabular}

Notes: G is growth rate of GDP. G Credit, G Export, G Import, G Labour Force and G Government Exp. are growth rate of respective items. With $D$ prefix they denote interaction with treatment time dummy. Treatment time period is mentioned in the column header. For treatment 2007-10, observations beyond 2010 are dropped and the comparison group is 2002-06. L.IGDP is lag of natural log of GDP. India Post is the interaction of India (country dummy) with post dummy (years indicated by column header). All items in local currency. We control for each country having two separate crisis dummy $(2008,2009) .{ }^{*}, * *$ and ${ }^{* * *}$ denotes significance at 10,5 and 1 percent respectively. 
Table 14: Panel Regressions In Growth: 62 Countries

\begin{tabular}{lcccccc}
\hline \hline & $(2012-16)$ & $(2012-16)$ & $(2012-16)$ & $(2007-10)$ & $(2007-10)$ & $(2007-10)$ \\
& $G$ & $G$ & $G$ & $G$ & $G$ & $G$ \\
\hline G Import & $0.0996^{* * *}$ & $0.105^{* * *}$ & $0.0792^{* * *}$ & $0.101^{* * *}$ & $0.115^{* * *}$ & $0.0706^{* * *}$ \\
& $(0.001)$ & $(0.000)$ & $(0.003)$ & $(0.009)$ & $(0.001)$ & $(0.007)$ \\
G Export & 0.0188 & 0.0184 & -0.00403 & -0.00186 & -0.00708 & $-0.0574^{* *}$ \\
& $(0.493)$ & $(0.471)$ & $(0.848)$ & $(0.973)$ & $(0.892)$ & $(0.029)$ \\
G Credit & $0.0424^{* * *}$ & $0.0404^{* * *}$ & $0.0412^{* * *}$ & $0.0447^{* * *}$ & $0.0428^{* * *}$ & $0.0413^{* * *}$ \\
& $(0.000)$ & $(0.000)$ & $(0.000)$ & $(0.000)$ & $(0.000)$ & $(0.000)$ \\
DG Import & 0.0198 & -0.00240 & 0.0185 & 0.00797 & -0.0125 & 0.0288 \\
& $(0.544)$ & $(0.935)$ & $(0.484)$ & $(0.822)$ & $(0.696)$ & $(0.241)$ \\
DG Export & 0.0375 & 0.0431 & $0.0668^{* * *}$ & 0.0405 & 0.0479 & $0.0927^{* * *}$ \\
& $(0.281)$ & $(0.172)$ & $(0.009)$ & $(0.489)$ & $(0.395)$ & $(0.001)$ \\
DG Credit & 0.0219 & 0.00791 & 0.0182 & -0.0211 & -0.0159 & -0.0143 \\
& $(0.190)$ & $(0.666)$ & $(0.334)$ & $(0.300)$ & $(0.395)$ & $(0.494)$ \\
India Post & $1.637^{* * *}$ & $1.572^{* * *}$ & $1.399^{* * *}$ & $1.911^{* * *}$ & $2.021^{* * *}$ & $0.737^{*}$ \\
& $(0.000)$ & $(0.000)$ & $(0.002)$ & $(0.004)$ & $(0.003)$ & $(0.065)$ \\
G Government Exp. & & $0.0351^{* *}$ & $0.0209^{* *}$ & & $0.0392^{* * *}$ & $0.0181^{* *}$ \\
& & $(0.014)$ & $(0.043)$ & & $(0.003)$ & $(0.042)$ \\
G Labour Force & & 0.0325 & 0.0149 & & 0.00754 & -0.0271 \\
& & $(0.551)$ & $(0.797)$ & & $(0.916)$ & $(0.694)$ \\
DG Government Exp. & & $0.0723^{*}$ & $0.0891^{* *}$ & & -0.0204 & 0.000281 \\
& & $(0.084)$ & $(0.015)$ & & $(0.621)$ & $(0.995)$ \\
DG Labour Force & & -0.00537 & 0.0494 & & 0.105 & 0.113 \\
& & $(0.941)$ & $(0.543)$ & & $(0.325)$ & $(0.318)$ \\
L.IGDP & & & $-3.234^{* * *}$ & & & -3.067 \\
& & & $(0.000)$ & & & $(0.208)$ \\
Constant & $2.557^{* * *}$ & $2.396^{* * *}$ & $93.65^{* * *}$ & $2.608^{* * *}$ & $2.466^{* * *}$ & 89.45 \\
& $(0.000)$ & $(0.000)$ & $(0.000)$ & $(0.000)$ & $(0.000)$ & $(0.191)$ \\
\hline$R^{2}$ & 0.495 & 0.517 & 0.526 & 0.535 & 0.549 & 0.576 \\
Observations & 930 & 930 & 868 & 558 & 558 & 496 \\
\hline \hline
\end{tabular}

Notes: G is growth rate of GDP. G Credit, G Export, G Import, G Labour Force and G Government Exp. are growth rate of respective items. With $D$ prefix they denote interaction with treatment time dummy. Treatment time period is mentioned in the column header. For treatment 2007-10, observations beyond 2010 are dropped and the comparison group is 2002-06. L.IGDP is lag of natural log of GDP. India Post is the interaction of India (country dummy) with post dummy (years indicated by column header). All items in local currency. $*, * *$ and *** denotes significance at 10,5 and 1 percent respectively. 
Table 15: Panel Regressions In Growth: With Country Crisis Dummy: 62 Countries

\begin{tabular}{|c|c|c|c|}
\hline & $\begin{array}{c}\text { (2007-10: Crisis Dummy) } \\
\text { G }\end{array}$ & $\begin{array}{l}\text { (2007-10: Crisis Dummy) } \\
\text { G }\end{array}$ & $\begin{array}{c}\text { (2007-10: Crisis Dummy) } \\
\text { G }\end{array}$ \\
\hline G Import & $\begin{array}{l}0.103^{* *} \\
(0.023)\end{array}$ & $\begin{array}{c}0.121^{* * *} \\
(0.001)\end{array}$ & $\begin{array}{c}0.0739^{* * *} \\
(0.008)\end{array}$ \\
\hline G Export & $\begin{array}{l}0.00534 \\
(0.932)\end{array}$ & $\begin{array}{c}-0.000103 \\
(0.999)\end{array}$ & $\begin{array}{r}-0.0432 \\
(0.100)\end{array}$ \\
\hline G Credit & $\begin{array}{c}0.0442^{* * *} \\
(0.007)\end{array}$ & $\begin{array}{c}0.0426^{* * *} \\
(0.006)\end{array}$ & $\begin{array}{c}0.0444^{* * *} \\
(0.000)\end{array}$ \\
\hline DG Import & $\begin{array}{c}-0.00742 \\
(0.853)\end{array}$ & $\begin{array}{l}-0.0327 \\
(0.372)\end{array}$ & $\begin{array}{l}0.0106 \\
(0.743)\end{array}$ \\
\hline DG Export & $\begin{array}{l}0.0226 \\
(0.721)\end{array}$ & $\begin{array}{l}0.0306 \\
(0.602)\end{array}$ & $\begin{array}{l}0.0618^{*} \\
(0.097)\end{array}$ \\
\hline DG Credit & $\begin{array}{l}-0.0345 \\
(0.254)\end{array}$ & $\begin{array}{l}-0.0319 \\
(0.266)\end{array}$ & $\begin{array}{r}-0.0340 \\
(0.271)\end{array}$ \\
\hline India Post & $\begin{array}{l}3.146^{* * *} \\
(0.000)\end{array}$ & $\begin{array}{c}3.263^{* * *} \\
(0.000)\end{array}$ & $\begin{array}{c}2.096^{* * *} \\
(0.000)\end{array}$ \\
\hline G Government Exp. & & $\begin{array}{c}0.0495^{* * *} \\
(0.002)\end{array}$ & $\begin{array}{c}0.0297^{* * *} \\
(0.003)\end{array}$ \\
\hline G Labour Force & & $\begin{array}{l}0.0471 \\
(0.620)\end{array}$ & $\begin{array}{l}0.0345 \\
(0.673)\end{array}$ \\
\hline DG Government Exp. & & $\begin{array}{l}-0.0277 \\
(0.172)\end{array}$ & $\begin{array}{r}-0.0156 \\
(0.537)\end{array}$ \\
\hline DG Labour Force & & $\begin{array}{l}0.0124 \\
(0.908)\end{array}$ & $\begin{array}{l}0.0155 \\
(0.899)\end{array}$ \\
\hline L.IGDP & & & $\begin{array}{l}-2.786 \\
(0.310)\end{array}$ \\
\hline Constant & $\begin{array}{c}-3.285^{* * *} \\
(0.001)\end{array}$ & $\begin{array}{c}-3.813^{* * *} \\
(0.000)\end{array}$ & $\begin{array}{l}75.18 \\
(0.329)\end{array}$ \\
\hline$R^{2}$ & 0.715 & 0.734 & 0.812 \\
\hline Observations & 558 & 558 & 496 \\
\hline
\end{tabular}

Notes: G is growth rate of GDP. G Credit, G Export, G Import, G Labour Force and G Government Exp. are growth rate of respective items. With $D$ prefix they denote interaction with treatment time dummy. Treatment time period is mentioned in the column header. For treatment 2007-10, observations beyond 2010 are dropped and the comparison group is 2002-06. L.IGDP is lag of natural log of GDP. India Post is the interaction of India (country dummy) with post dummy (years indicated by column header). All items in local currency. We control for each country having two separate crisis dummy $(2008,2009) .{ }^{*}, * *$ and ${ }^{* * *}$ denotes significance at 10,5 and 1 percent respectively. 
Table 16: Panel Regressions In Levels: 82 Countries

\begin{tabular}{lcccccc}
\hline \hline & $(2012-16)$ & $(2012-16)$ & $(2007-10)$ & $(2007-10)$ & $(2007-10)$ & $(2007-10)$ \\
& $G D P$ & $G D P$ & $G D P$ & GDP & GDP & GDP \\
\hline Import & $0.176^{* * *}$ & $0.142^{* * *}$ & $0.152^{* * *}$ & $0.149^{* * *}$ & $0.148^{* * *}$ & $0.147^{* * *}$ \\
& $(0.008)$ & $(0.000)$ & $(0.000)$ & $(0.000)$ & $(0.002)$ & $(0.000)$ \\
Export & 0.0345 & 0.0423 & 0.0299 & 0.00767 & 0.0384 & 0.0153 \\
& $(0.425)$ & $(0.126)$ & $(0.401)$ & $(0.821)$ & $(0.375)$ & $(0.687)$ \\
Credit & $0.131^{* * *}$ & $0.101^{* * *}$ & $0.0536^{* * *}$ & $0.0655^{* * *}$ & $0.0532^{* *}$ & $0.0653^{* * *}$ \\
& $(0.000)$ & $(0.000)$ & $(0.007)$ & $(0.003)$ & $(0.020)$ & $(0.008)$ \\
D Import & 0.0197 & 0.0261 & 0.0153 & 0.0303 & 0.00428 & 0.0161 \\
& $(0.641)$ & $(0.455)$ & $(0.570)$ & $(0.236)$ & $(0.887)$ & $(0.561)$ \\
D Export & 0.0193 & 0.0233 & 0.0216 & 0.0105 & 0.0335 & 0.0250 \\
& $(0.691)$ & $(0.522)$ & $(0.423)$ & $(0.691)$ & $(0.280)$ & $(0.387)$ \\
D Credit & $-0.0343^{* * *}$ & -0.0108 & $-0.0356^{* * *}$ & -0.0135 & $-0.0361^{* * *}$ & -0.0132 \\
& $(0.006)$ & $(0.494)$ & $(0.000)$ & $(0.122)$ & $(0.000)$ & $(0.172)$ \\
India Post & $0.149^{* * *}$ & $0.128^{* * *}$ & $0.0553^{* * *}$ & $0.0678^{* * *}$ & $0.0690^{* * *}$ & $0.0847^{* * *}$ \\
& $(0.000)$ & $(0.000)$ & $(0.000)$ & $(0.001)$ & $(0.000)$ & $(0.000)$ \\
Government Exp. & & $0.150^{* * *}$ & & $0.0703^{* *}$ & & $0.0700^{* *}$ \\
& & $(0.008)$ & & $(0.027)$ & & $(0.035)$ \\
Labour Force & & $0.526^{* * *}$ & & $0.431^{* * *}$ & & $0.450^{* * *}$ \\
& & $(0.000)$ & & $(0.000)$ & & $(0.000)$ \\
D Government Exp. & & $-0.0406^{* *}$ & & $-0.0274^{* * *}$ & & $-0.0278^{* * *}$ \\
& & $(0.019)$ & & $(0.003)$ & & $(0.005)$ \\
Constant & $18.11^{* * *}$ & $7.615^{* * *}$ & $21.28^{* * *}$ & $13.01^{* * *}$ & $21.23^{* * *}$ & $12.56^{* * *}$ \\
& $(0.000)$ & $(0.000)$ & $(0.000)$ & $(0.000)$ & $(0.000)$ & $(0.000)$ \\
\hline$R^{2}$ & 0.879 & 0.930 & 0.893 & 0.916 & 0.922 & 0.940 \\
Observations & 1230 & 1230 & 738 & 738 & 738 & 738 \\
\hline \hline
\end{tabular}

Notes: GDP is natural logarithm of GDP. Credit, Export, Import, Labour Force and Government Exp. are natural logarithm of respective items. With $D$ prefix they denote interaction with treatment time dummy. Treatment time period is mentioned in the column header. For treatment 2007-10, observations beyond 2010 are dropped and the comparison group is 2002-06. India Post is the interaction of India (country dummy) with post dummy (years indicated by column header). All items in local currency. Last two columns gives the result obtained after inclusion of interaction of country and two crisis dummy $(2008,2009) .{ }^{*}, * *$ and $* * *$ denotes significance at 10, 5 and 1 percent respectively. 
Table 17: Panel Regressions In Levels: 62 Countries

\begin{tabular}{lcccccc}
\hline \hline & $(2012-16)$ & $(2012-16)$ & $(2007-10)$ & $(2007-10)$ & $(2007-10)$ & $(2007-10)$ \\
& $G D P$ & $G D P$ & $G D P$ & $G D P$ & GDP & GDP \\
\hline Import & 0.116 & $0.138^{* * *}$ & $0.154^{* * *}$ & $0.164^{* * *}$ & $0.146^{* * *}$ & $0.157^{* * *}$ \\
& $(0.121)$ & $(0.001)$ & $(0.000)$ & $(0.000)$ & $(0.008)$ & $(0.001)$ \\
Export & 0.0665 & 0.0323 & 0.0320 & 0.00286 & 0.0342 & 0.00335 \\
& $(0.160)$ & $(0.312)$ & $(0.379)$ & $(0.934)$ & $(0.476)$ & $(0.936)$ \\
Credit & $0.136^{* * *}$ & $0.101^{* * *}$ & $0.0507^{* *}$ & $0.0673^{* * *}$ & $0.0509^{*}$ & $0.0695^{* *}$ \\
& $(0.000)$ & $(0.000)$ & $(0.025)$ & $(0.009)$ & $(0.058)$ & $(0.022)$ \\
D Import & 0.0631 & 0.0144 & 0.0315 & 0.0197 & 0.0230 & 0.00641 \\
& $(0.170)$ & $(0.709)$ & $(0.296)$ & $(0.458)$ & $(0.513)$ & $(0.837)$ \\
D Export & -0.0278 & 0.0243 & 0.00828 & 0.0198 & 0.0169 & 0.0312 \\
& $(0.586)$ & $(0.530)$ & $(0.789)$ & $(0.510)$ & $(0.639)$ & $(0.354)$ \\
D Credit & $-0.0287^{*}$ & -0.0139 & $-0.0396^{* * *}$ & $-0.0241^{* *}$ & $-0.0392^{* * *}$ & $-0.0229^{* *}$ \\
& $(0.062)$ & $(0.363)$ & $(0.000)$ & $(0.014)$ & $(0.000)$ & $(0.033)$ \\
India Post & $0.135^{* * *}$ & $0.130^{* * *}$ & $0.0546^{* * *}$ & $0.0732^{* * *}$ & $0.0713^{* * *}$ & $0.0938^{* * *}$ \\
& $(0.000)$ & $(0.000)$ & $(0.000)$ & $(0.000)$ & $(0.000)$ & $(0.000)$ \\
Government Exp. & & $0.148^{* *}$ & & $0.0679^{* *}$ & & $0.0658^{* *}$ \\
& & $(0.018)$ & & $(0.042)$ & & $(0.044)$ \\
Labour Force & & $0.543^{* * *}$ & & $0.505^{* * *}$ & & $0.527^{* * *}$ \\
& & $(0.000)$ & & $(0.000)$ & & $(0.001)$ \\
D Government Exp. & & -0.0248 & & -0.0169 & & -0.0157 \\
& & $(0.194)$ & & $(0.192)$ & & $(0.261)$ \\
Constant & $18.88^{* * *}$ & $7.826^{* * *}$ & $21.47^{* * *}$ & $11.69^{* * *}$ & $21.68^{* * *}$ & $11.48^{* * *}$ \\
& $(0.000)$ & $(0.000)$ & $(0.000)$ & $(0.000)$ & $(0.000)$ & $(0.000)$ \\
\hline$R^{2}$ & 0.893 & 0.939 & 0.903 & 0.927 & 0.929 & 0.948 \\
Observations & 930 & 930 & 558 & 558 & 558 & 558 \\
\hline \hline
\end{tabular}

Notes: GDP is natural logarithm of GDP. Credit, Export, Import, Labour Force and Government Exp. are natural logarithm of respective items. With $D$ prefix they denote interaction with treatment time dummy. Treatment time period is mentioned in the column header. For treatment 2007-10, observations beyond 2010 are dropped and the comparison group is 2002-06. India Post is the interaction of India (country dummy) with post dummy (years indicated by column header). All items in local currency. Last two columns gives the result obtained after inclusion of interaction of country and two crisis dummy $(2008,2009) .{ }^{*}, * *$ and $* * *$ denotes significance at 10, 5 and 1 percent respectively. 


\section{References}

[1] Bloom, D.E. and Finlay, J.E., 2009. Demographic Change and Economic Growth in Asia. Asian Economic Policy Review, Vol. 4, Issue No. 1, pp.45-64.

[2] Dholakia, Ravindra, 2015. Double Deflation Method and Growth of Manufacturing, Economic and Political Weekly, Vol. 50, Issue No. 41, 10.

[3] Dholakia, Ravindra, R. Nagaraj, and Manish Pandya, 2018. Manufacturing Output in New GDP Series, Economic and Political Weekly, Vol. 53, Issue No. 35, 01 Sep, 2018

[4] Goyal, Ashima, 2015. Measuring Indian Growth: Why the Data Should Be Doubted Less, Economic and Political Weekly, Vol. 50, Issue No. 32, 08 Aug, 2015

[5] Nagaraj, R and T N Srinivasan, 2016. Measuring India's GDP Growth: Unpacking the Analytics \& Data Issues behind a Controversy that Refuses to Go Away, India Policy Forum.

[6] Subramanian, Arvind, 2019. India's GDP Mis-estimation: Likelihood, Magnitudes, Mechanisms, and Implications, CID Faculty Working Paper No. 354

[7] Goyal, Ashima. and Abhishek Kumar, 2017. A DSGE Model-Based Analysis of the Indian Slowdown. Indira Gandhi Institute of Development Research.

[8] Goyal, Ashima. and Abhishek Kumar, 2018. Active Monetary Policy and the Slowdown: Evidence from DSGE Based Indian Aggregate Demand and Supply. The Journal of Economic Asymmetries, 17, pp.21-40.

[9] Goyal, Ashima. and Abhishek Kumar, 2019. Overreaction in Indian Monetary Policy. Economic and Political Weekly, Vol 54, No 12 